\title{
Tarja branca: memória e narrativas sensíveis em práticas de cinema no hospital
}

\section{Cintia Sanmartin Fernandes}

Socióloga. Concluiu pós-doutorado pela Escola de Comunicação da Universidade Federal do Rio de Janeiro (UFRJ) e pelo Programa de Comunicação e Semiótica na Pontifícia Universidade Católica de São Paulo (PUC-SP). Doutora e mestre em Sociologia Política pela Universidade Federal de Santa Catarina (UFSC). Realizou estágio no Centre D’Étude sur L'Actuel et Le Quotidien (CEAQ) da Université René Descartes - Paris V (Sorbonne). É professora adjunta da Faculdade de Comunicação Social (FCS-Uerj) e do Programa de PósGraduação em Comunicação da Universidade do Estado do Rio de Janeiro (PPGCOM-Uerj). É coordenadora do PPGCOM-Uerj, vice-coordenadora do grupo de pesquisa Comunicação, Arte e Cidade (CAC) e pesquisadora associada do Núcleo de Estudos e Projetos em Comunicação (NEPCOM-UFRJ), onde desenvolve o projeto "Culturas Urbanas e Comunicação no Rio de Janeiro".

E-mail: cintia@lagoadaconceicao.com

\section{Tatiane Mendes}

Doutoranda em Comunicação Social pelo PPGCOM-Uerj. Mestre em Mídia e Cotidiano pela Universidade Federal Fluminense, onde desenvolveu pesquisa sobre Cinema e Educação. Professora de comunicação social, coordenadora do Cineclube do Programa de Pós-Graduação em Mídia e Cotidiano da Universidade Federal Fluminense (PPGMC/UFF) e pesquisadora do Laboratório de Comunicação, Arte e Cidade (CAC-Uerj) e do Laboratório de Investigação de Comunicação Comunitária e Publicidade Social (LACCOPS-UFF). E-mail: tatunha@gmail.com
Resumo: Quais são os possíveis cruzamentos na ação da memória como um espaço entre o eu e o outro? Este trabalho investiga o poder de compartilhamento de memória na construção de narrativas sensíveis, baseadas em atividades de cinema em enfermarias do Hospital Universitário Clementino Fraga Filho, no Rio de Janeiro. As práticas são resultantes da apresentação do documentário Tarja branca, dirigido por Cacau Rhoden, durante o ano de 2016. Como metodologia de pesquisa, optou-se pela cartografia segundo os pressupostos de Virgínia Kastrup.

Palavras-chave: Cinema no Hospital; Tarja branca; Memória; Narrativas.

\section{Tarja branca: memory and sensitive narratives in cinema practices at the hospital}

Abstract: What are the possible crossings in the action of memory as a space between the self and others? This work investigates the power of memory sharing in the construction of sensitive narratives, based on cinema activities carried out in Hospital Universitário Clementino Fraga Filho (RJ) nurseries. The practices are a result of the presentation of the documentary Tarja branca (Cacau Rhoden, 2014) during the year of 2016. The chosen research methodology was the cartography concepts according to the assumptions of Virginia Kastrup.

Keywords: Cinema at the Hospital; Tarja branca; Memory; Narratives. 
${ }^{1}$ Iniciativa do Laboratório de Educação, Cinema e Audiovisual (Lecav-UFRJ), sob coordenação da professora Adriana Fresquet. Ver: <http://www.cinead. org/>. Acesso em 14 jan. 2017.

\section{Introdução}

Com o olhar perdido, a coreógrafa Andrea Jabor descreve a foto mais representativa da sua infância. Emocionada, ela narra em detalhes a roupa, o contexto e os sentimentos que a acompanham na contemplação da imagem e da liberdade daquele tempo. $O$ detalhe: ela não tem a foto nas mãos. Está na memória. É exatamente desse lugar de afeto e sensibilidade que este artigo parte para analisar as experiências fílmicas com o filme Tarja branca durante acompanhamento do projeto Cinema no Hospital. O longa-metragem, construído em um viés documental, tem como premissa a importância da brincadeira como linguagem fundamental do indivíduo. Ao longo do filme, uma série de entrevistados descreve sua relação com as memórias de infância no cotidiano atual. Mais do que uma sucessão de falas de especialistas, o filme opta pelo relato de experiências no acesso às memórias de cada um. Assim, psicanalistas, professores, artistas plásticos e atores se juntam nas brincadeiras de roda, nos jogos de pião e pipa, tomando a rua, correndo por praias azuis e jardins ensolarados. Estão todos ali, crianças e adultos, unidos pela emergência da narrativa.

Toma-se como ponto de partida o projeto Cinema no Hospital, conjunto de atividades práticas de cinema em enfermarias que ocorre semanalmente, desde 2015, no Hospital Universitário Clementino Fraga Filho (HUCFF), localizado na cidade do Rio de Janeiro. A iniciativa - que inclui a exibição de filmes e rodas de conversa no ambiente hospitalar - é do Laboratório Cinema para Aprender e Desaprender (Cinead) $)^{1}$. As atividades ocorrem geralmente nas enfermarias geriátricas do hospital. Para efeito deste artigo serão analisadas as práticas com o filme Tarja branca durante exibição nas enfermarias e em reuniões com o grupo de pacientes portadores de hanseníase. Em cada uma das sessões o filme foi exibido para uma média de dez pessoas (entre funcionários, pacientes e acompanhantes) e, após os créditos, uma atividade foi proposta: que os presentes mostrassem ou tentassem descrever as fotos mais representativas da infância. Em todas as sessões a emoção tomou conta da fala, as expressões mudaram, algumas vozes embargaram e houve quem não contivesse as lágrimas. A mobilização foi bastante representativa, o que possibilitou criar uma narrativa em comum, unindo afeto e memórias.

O tempo vivido tornou-se então narrativa compartilhada por todos. Quem afinal não tinha uma imagem que pudesse descrever os primeiros anos de vida? Sob o peso da história, muitos pareciam analisar suas trajetórias, particularmente quando questionados sobre o que diriam àquela criança que havia sido descrita se pudessem vê-la e o que ela diria, se pudesse. Em todas as vezes que essa pergunta foi feita, estabeleceu-se um processo de narração, compartilhamento e aproximação entre os participantes. Entre pacientes, funcionários, acompanhantes e entrevistados do filme criou-se um lugar em comum, parecendo se quebrar por alguns momentos o limite entre o eu e o outro, entre o filme e a realidade.

Fundamentado na experiência descrita, o objetivo é compreender, no atravessamento e na expansão da narrativa fílmica no ambiente do hospital, a construção coletiva de memória. Mais do que isso. Observa-se que a proposta do filme, ao intermediar afetos e vivências, possibilita a criação de narrativas, imagens da memória não vistas, mas sentidas e vivenciadas por todos. Logo, se o filme se oferece a tal experimentação, constrói o que Andrea França Martins (2006) - observando a potência do cinema em criar relações entre o sujeito e o espaço - caracteriza como "territórios sensíveis", isto é: ambientes de compartilhamento simbólico, onde as experiências realizadas são da ordem do imaginário e do afetivo, promovendo vinculações entre os sujeitos.

Para tentar delinear a experiência, recorremos ao processo multimetodológico de associar a revisão bibliográfica à cartografia, segundo os pressupostos de 
Passos, Kastrup e Escóssia (2009). Dessa forma, os autores compreendem o ato de cartografar como desterritorialização, na qual o pesquisador necessita deslocar o olhar para observar o fenômeno e, em consequência, entender a complexidade de um corpus formado não só por sujeitos inseridos em um ambiente a um só tempo imprevisível e instável com a enfermaria de um hospital, mas pelas sociabilidades decorrentes dessas interações.

Os autores também percebem a necessidade de aproximação do pesquisador do objeto pesquisado para extrair sentidos, "abrir-se para o sensível" (Ibid.: 9), dialogando a um só tempo com as perspectivas de Michel Maffesoli (1998), sobre a experiência sensível, e a ideia de territórios sensíveis, de Andréa França Martins (2006). Assim como Maffesoli entende que a experiência contemporânea permite identificar as emoções como fonte de investigação, também França observa que o cinema se torna o espaço para a emergência de tais experiências sensíveis. A seu modo, os autores apontam para a prevalência das emoções e do afeto como criação de conexões entre o sujeito e o espaço, potência de territorialidades. Abrirse para o sensível será, assim, a condição de produção do trabalho em questão.

Com Passos, Kastrup e Escóssia (2009) compreende-se a cartografia como intervenção, método que se faz durante o percurso de pesquisa, mergulhando na experiência que será observada e reforçando a técnica da observação participante. Para aproximar-se dos pressupostos da razão sensível, que não afasta o sujeito do objeto estudado, será fundamental, então, colocar também um tanto de si na pesquisa. Cabe relacionar aos sujeitos também o pesquisador, uma vez que na opção teórica e metodológica optamos não pelo "saber sobre", mas pelo "saber com" (PASSOS; KASTRUP; ESCÓSSIA, 2009), passível de gerar pertencimento.

${ }^{2}$ Disponível em: <https://goo.gl/ rypRdH>. Acesso em: 14 jan. 2017.
Como forma de identificar a possibilidade de criação de territórios sensíveis entre os espaços, foram observadas as relações entre os sujeitos participantes das práticas. Para essa análise, foram utilizadas as descrições dos relatos feitas durante as práticas e registradas em um blog ${ }^{2}$. De tal modo, acreditamos que no intercâmbio de experiências há a possibilidade de alcançar, na relação entre sujeitos, memórias, práticas e a potência de criação de vinculações.

Intenciona-se desvendar se as narrativas memoriais promovem uma experiência estética compartilhada. Ou seja, a ideia é refletir sobre o lugar do estético como um caminho que se traça entre o sujeito e o mundo, passível de criar um nexo atrativo entre o público e suas próprias memórias, por meio da narrativa do afeto pelo recorte específico da diretora Cacau Rhoden, ao construir o filme Tarja branca (2014). Pensamos a obra fílmica em questão como uma vivência que pode extrapolar as imagens relatadas em fragmentos de memória já registradas e alcançar o público, sendo ressignificada e tornando-se experiência estética coletiva.

Entendemos que esta análise se insere na lógica da experiência sensível, tomando o caminho que parte do fenômeno, com suas distintas nuances. Apontamos para diálogos que se constituem entre o filme e os espectadores e entre as sensibilidades que emanam. Ao abrir o "baú de lembranças" cada participante possibilita ao outro compartilhar de sua dor ou de sua felicidade. Identifica-se então, em Maffesoli (1998), a emoção compartilhada como passível de revelar a compreensão a partir de sua razão interna, só sugerida na ação do observador que pode se tornar, em alguma medida, cúmplice de uma experiência.

Lugares do afeto, as imagens resgatadas em fragmentos de tempo falam e fazem falar. Convocam o olhar e a alma, de modo semelhante ao que o semiólogo Roland Barthes (1984: 46), ao pensar a fotografia, definira como "punctum", ou o elemento casual "que punge", o detalhe na imagem que, por uma força que concentra em si, atinge o sujeito e lhe mobiliza involuntariamente o afeto. Ocorre que essa imagem não reside materialmente nas mãos de quem as descreve, apenas na memória. É, contudo, uma realidade em si. 
Assume-se com Henri Bergson (1999: 17) que a "afetividade supõe que o corpo seja coisa distinta de um ponto matemático e dê a ela volume no espaço", e que a memória constrói a duração no tempo. Compreendemos assim que o sujeito inserido em uma experiencia sensível, afetiva, pode construir narrativas de si, de modo a criar experiencias de tempo, ou durações (como pensa Bergson) e, em alguma medida, compartilhar e transformar visões de mundo.

Ao acessar a memória - esse espaço onde as imagens constroem idas e vindas do sujeito - é possível localizar narrativas de si, mergulhos possíveis por meio das práticas com o cinema. E se o filme abre diálogos para a partilha de sentido e sensibilidades pautadas na afetação do público pela história íntima, possibilita que venham à tona memórias de quem assiste ao filme e se emociona ao ver as memórias alheias. Dessa maneira, em Tarja branca sugere-se uma possibilidade de aproximação com o público não somente devido ao peso da dor que permeia a narrativa, mas na troca que se propõe entre o espectador e as personagens, lugar onde cada uma visita suas próprias memórias, traçando uma experiência singular, não de fuga do cotidiano, mas de mergulho e reflexão a partir da narrativa de cada entrevistado.

Na narrativa, dor e alegria partem da tela para a enfermaria, se abrem ao público, que é convidado a sensibilizar-se junto com cada fala. Mais do que isso, é convidado a retomar suas memórias e ressignificá-las no contato com as memórias alheias, criando sua própria experiência, que se apresenta singular, estética. A emoção é, desse modo, a força que consolida o espaço em comum, produzindo empatia e alteridade. Cabe então, entre memória e afeto, iniciar o percurso de investigação.

\section{Tarja branca: modos de uso}

O filme começa fora de foco, com câmera fixa e os áudios de algum entrevistado sobre a perda da essência ao perdermos o direito de brincar. Em um corte seco, o espectador é transportado para a aceleração do cotidiano, em imagens de túneis, construções, engarrafamentos e dias cinzentos - a triste metáfora da

${ }^{3}$ Termo técnico para a fusão de imagens. modernidade. Em um sutil crossfade ${ }^{3}$, a diretora nos convida a mergulhar em um outro tempo, trazendo para a tela um plano geral da rua de uma cidade do interior. Ao lado, as cores das casas substituem o cinza do asfalto e trazem a fala de Lydia Hortélio, professora e pesquisadora. Mas Hortélio não traz em sua fala abordagens teóricas ou metodológicas. Ela fala de suas memórias de infância no interior do Bahia. O mesmo se dá com David Reeks, documentarista norteamericano, sobre a infância no subúrbio. Logo, Antônio Nobrega (multiartista) e Renata Meirelles (pesquisadora) sucedem-se na tela, sob o mesmo método do crossfade e com a mesma linha narrativa: as memórias da infância. $O$ traço mais curioso das primeiras falas é que os entrevistados não parecem olhar diretamente para a câmera. Há um ponto para onde converge o olhar, que não parece estar na frente de seus olhos, mas em algum lugar que a câmera não consegue captar. Quando descrevem a infância as expressões mudam, sorriem, como se mergulhassem dentro deles mesmos.

Vem então a primeira inserção de imagens de arquivo, ilustrando as histórias contadas. Ali se vê um bebê entrando no mar, exatamente como Meirelles relata. E para o espectador não importa saber se aquela imagem tem alguma relação real com Renata, se é um menino ou uma menina (trata-se de um menino). Ao ter sua fala vinculada à imagem, sua memória descrita é apropriada pelo público, para criar, com as imagens de arquivo, uma percepção particular da infância da pesquisadora. Na sequência seguinte, Wandi Doratiotto, músico e ator, viaja em suas memórias também e, talvez na persistência da imagem anterior da praia, é possível enxergar o mesmo menino na fala de Doratiotto, ação reforçada pelo uso do primeiro plano como enquadramento de câmera, o que aproxima o público das emoções do entrevistado. 
Logo aparecem imagens de crianças pulando corda e brincando de pião, entrecortadas pela fala de Helder Vasconcelos, revelando suas brincadeiras preferidas. Em plano médio, ele também parece olhar para si quando fala dos jogos de infância, que dialogam com uma percepção do tempo diferente do cotidiano dos adultos. Assim também é a fala da pedagoga Maria Amélia Pereira, que relata sua memória mais forte de infância: castelos de areia, construídos no movimento leve das mãos que ela move, para criar em frente à câmera um castelo imaginário, pingando água do mar, enquanto mantêm os mesmos olhos quase sempre perdidos e mergulhados nas memórias de cada entrevistado. E então ocorre um corte, de ritmo, áudio e narrativas. Nas falas de José Simão (jornalista) e Marcelino Freire (escritor) outro universo de brincadeiras se revela, agora pelo viés do imaginário. Não por acaso os dois entrevistados revelam, entre falas entrecortadas por imagens de livros, seu quintal de infâncias com a literatura. E ali o crossfade acentua o mergulho, ao fundir imagens de livros e de ondas do mar, em sons e imagens.

É nesse ciclo de imaginação e memória que o segundo bloco temático mostra as brincadeiras de roda, com a ilustre presença de Tia Maria do Jongo, Mestre Aguinaldo e o músico Alfredo Bello, e as revelações de que os territórios da infância não são somente belos, mas também dolorosos e difíceis. Ali o músico encontrou força para buscar as brincadeiras "infantis" já na idade adulta. E é nesse momento que um dos entrevistados faz dialogar a brincadeira com o fenômeno humano, de estar vivo e produzir significados, aqui associados a expressões culturais como festas, jogos e danças de rua nos mais variados cantos do país. No aproximar do "eu" e do mundo os entrevistados falam sobre a conexão entre pessoas, na formação do sujeito como ser relacional, ético, estético e pensante, por inteiro alguém que traz de si o melhor das memórias, das brincadeiras, de um ser "em comum" que se faz na força da brincadeira. E é ali que a narrativa sonora suavemente se faz background e deixa que cada entrevistado aponte a potência política do ato de brincar e do perigo do adulto que não se firma como um ser brincante, social e sensível. Na fala de Lydia Hortélio, o processo de brincar é interrompido pela necessidade funcionalista de produção contemporânea.

Enquanto imagens de brincadeiras se sucedem na tela, meninos constroem seus próprios brinquedos, criam seus mundos e o mundo cotidiano os subverte, retira-Ihes das mãos a potência de recriarem a si mesmos e chegarem aos seus semelhantes, criando novos estados de consciência. As possibilidades do corpo e do espírito estão em cada escolha do que e como brincar. Aqui o filme dá uma pausa nas falas e inicia uma sequência de aceleração de tempo com imagens de pessoas que observam a paisagem urbana, afastados da sua linguagem universal, que é brincar. E assim, na terceira parte do documentário, as falas, emolduradas pela ausência de qualquer outro som a não ser a captação direta do que é dito, apontam para a revolução necessária de brincar como processo formante. Logo é feito um corte e as reflexões de Lydia Hortélio são entrecortadas em crossfade por planos aéreos de uma grande metrópole onde, provavelmente, desaprendeuse a brincar como ato de dimensão humana, entre libertária e de resistência. No quarto bloco do filme, as falas são montadas de modo mais curto, seco, no contexto da tristeza, que, para todos os entrevistados, pode ser associada o ato de brincar. Como ilustração dos argumentos, as mesmas imagens de cidades, em um timing acelerado, carros e corpos que se cruzam, sem definição e a busca da felicidade como garantia para a medicalização dos sujeitos e das práticas, definidos por uma paisagem sonora melancólica. Essa mesma paisagem se desfaz em um novo crossfade para que os entrevistados falem de uma retomada - necessária para que se possa viver melhor. E a saída é voltar ao tempo da infância, segundo eles, a melhor parte do sujeito. É nesse último bloco que as memórias narradas se confundem com imagens de arquivos, fotografias e vídeos, e é fundamental trazer para a descrição a ideia barthesiana (BARTHES, 1984) de punctum, desse elemento que convoca o olhar. Aqui, apesar das muitas imagens da infância de cada um dos personagens, a fala que descreve cada foto não vai até a imagem. 


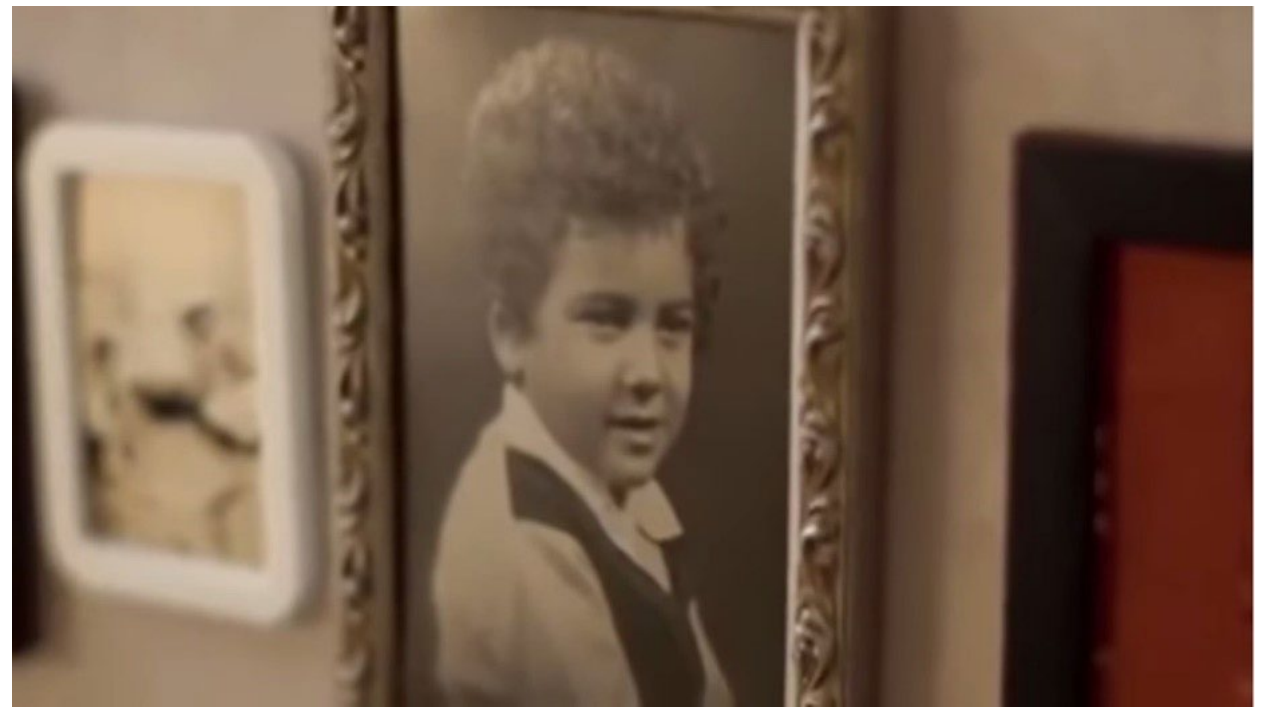

Figura 1: Fragmento do filme Tarja branca (TARJA..., 2017)

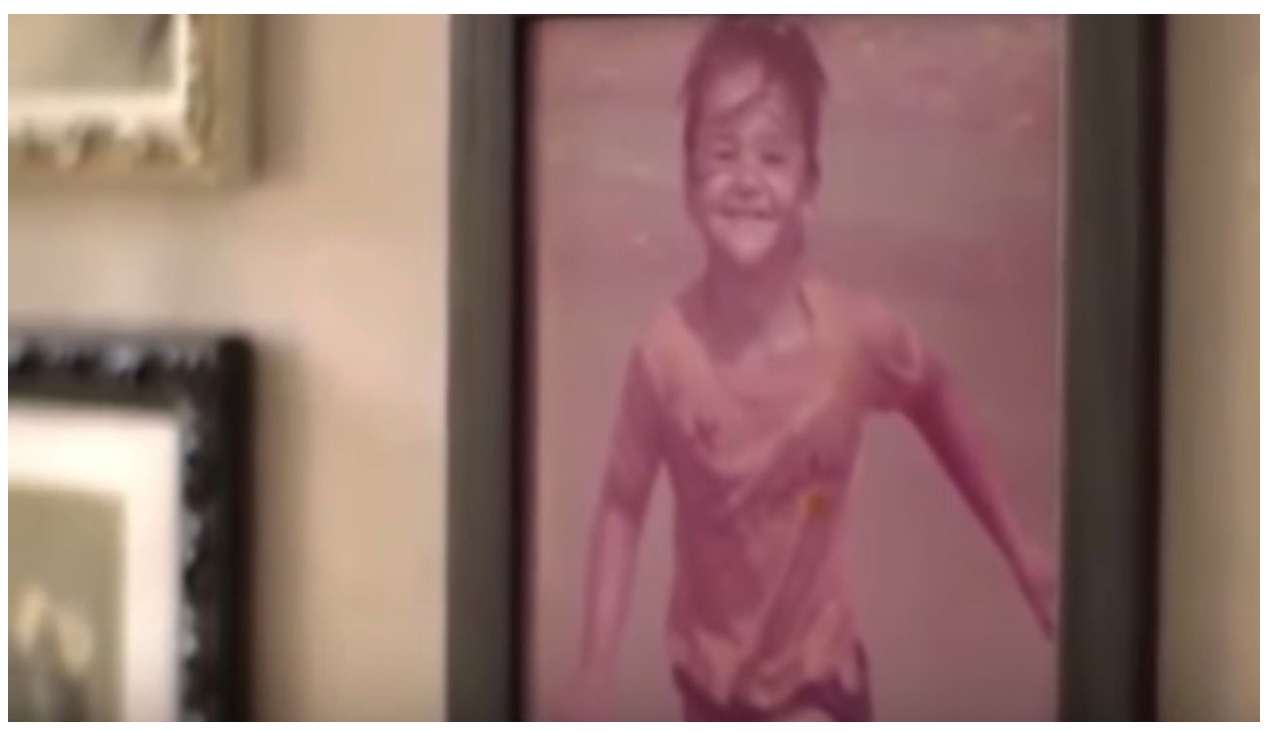

Figura 2: Fragmento do filme Tarja branca (TARJA..., 2017)

Ao contrário. Busca-a dentro de si, no elemento mais representativo, feito de afeto e memória, onde aquela criança é reconstruída, em sonhos e vontades. Ao adentrar esse território, as expressões se suavizam, os olhos umedecem, surge um leve sorriso em cada rosto. E assim, sem que se perceba, o remédio "Tarja branca" da infância foi definitivamente ministrado nas almas adultas dos que assistem e dos que participam do documentário.

\section{Cinema no Hospital: percurso sensível}

Como compreender mais profundamente o tempo das memórias faladas, sem associar as experiências às narrativas, que seriam, etimologicamente, o ato de dar a saber? No caso estudado, mais do que tornar conhecida uma história qualquer, o que se faz, ao estimular os participantes das oficinas a resgatarem suas memórias, é convidá-los a construir uma narrativa de si, permeada de lacunas e silêncios, mas também, e principalmente, de emoção. Pensando em conjunto com Leonor Arfuch (2010: 112), que se debruçara sobre o relato biográfico, a narrativa é a humanização do tempo, "forma por excelência de estruturação da vida", tempo que é personificado pelas vozes dos sujeitos que falam. Aqui é importante perceber não apenas o que se fala, mas o que se ouve. Em uma experiência sensível, como as vivenciadas no hospital, tão importante quanto falar é ouvir, tornando comuns as histórias contadas. Em acordo com Arfuch (Id.: 118), apoiase no caráter definitivamente narrativo da experiência. No momento em que o sujeito, acometido de alguma alteração no cotidiano que o prenda ao leito do 
${ }^{4}$ Disponível em: <https://goo.gl/ LGtSML>. Acesso em: 24 ago. 2015. hospital, é convidado a narrar-se, visitar suas memórias, sai de seu estado de silenciamento e dá a conhecer um pouco de si. Da mesma forma, na experiência coletiva há um compartilhar de diferentes tempos e cores de infância, fazendo das emoções e afetos o fio que entrelaça os sujeitos em suas falas. Assim, cada intervalo de silêncio realiza a tarefa que Bergson (1999) denominara a hesitação, ou o instante entre o estímulo do mundo e a resposta. No exíguo espaço de hesitação entre recepção e ação está o sujeito. Acessar a memória é assim atingir a percepção alheia, convocar a subjetividade, trazer à tona o afeto de coisas passadas, que são ressignificadas e trazidas ao tempo presente pelo expediente de serem narradas. Nesse intervalo, que Bergson pontua como não-cronológico, entre tempo e movimento, estão também as narrativas fílmicas que são produto das memórias dos sujeitos, na tela e fora dela.

Para o relato de experiências, em diálogo com o ideário cartográfico, é preciso realizar, como observam Passos, Kastrup e Escóssia (2009), a fase de rastreio do campo. Em primeiro lugar, é necessário compreender que a experiência do cinema no hospital envolve dialogar com um ambiente de intensa fragilidade humana, onde a presença do cinema se torna, muitas vezes, quase supérflua. Trata-se, afinal, de um hospital público do estado do Rio de Janeiro, inserido no Sistema Único de Saúde, o SUS. Criado em 1988 pela Constituição Federal Brasileira4, carrega no cerne a ideia de saúde como uma condição básica de cidadania, acesso à educação, saneamento, segurança e também comunicação. Ou seja: também, e principalmente, o direito a falar e ser ouvido. Contudo, ao adentrar os corredores semanalmente, não passará desapercebido o abandono das pilastras da entrada, os resquícios de obras inacabadas, que se sucedem sem descanso pelos corredores, a enorme fila de pacientes nos ambulatórios, circulando sem cessar os profissionais de saúde, sempre sem parar um só momento, tentando preencher com seus corpos as ausências, financeiras e afetivas. Por sua vez, as enfermarias mais parecem lugares de passagem, estufas no verão, geladas no inverno, onde se encolhem em seus cobertores pacientes que não podem apreciar a paisagem, posto que as janelas (concebidas para serem panorâmicas) estão cobertas de insulfilme descascado. Ser cidadão, nessas condições, parece algo irrealizável. Das salas onde as macas, cadeiras e comadres se acumulam aos corredores e onde as portas, envelhecidas, rangem e empenam, o cinema parece a menor e mais frágil das possibilidades emancipatórias. Ainda assim, é uma das raras iniciativas na enfermaria dos adultos, contrapondo-se ao número infinito de projetos e visitas direcionadas aos pacientes da ala infantil, por exemplo. Durante o tempo em que não é realizada a atividade do cinema, de modo geral observa-se a predominância de atividades individuais, como o uso da televisão ou o celular. Todos parecem manter-se em seu lugar.

Em cada visita, a enfermaria a ser escolhida precisa ser autorizada pelos enfermeiros. Depois disso, é importante verificar se não há televisões ligadas ou se os pacientes não estão dormindo, ou em procedimentos que não possam ser interrompidos. Feitas as verificações, cabe aos ocupantes da enfermaria decidir se querem ou não fazer parte da atividade. Em algumas situações, muitos negaram. Na maioria das vezes, a opção se dá pela que tem menos tubos e que seja mais próxima dos pacientes que estão acordados. Projetor montado, é hora de explicar o propósito do projeto e começar o filme. Em muitas visitas é a hora em que alguns acompanhantes posicionam a cadeira de frente para a "tela", com o celular na mão, e os pacientes interessados voltam os olhos, para poder acompanhar também. É comum os pacientes cochilarem, irem ao banheiro, atenderem o celular e até saírem da sala durante o filme, o que não quer dizer que não prestem atenção. Muitos perguntam, ao final da exibição, detalhes do que foi visto, comentam elementos e fazem observações. No caso de ser necessário interromper a sessão, por ocasião do adiantado da hora (o pedido do hospital é não estender a sessão muito além da hora de visitas) ou devido a um procedimento específico, há casos de pessoas que pedem para continuar exibindo o filme até o final. Esse é o caso de Tarja branca. 
Nas primeiras vezes em que se projetou o filme, a ideia era propor uma atividade além da projeção. Explica-se. $O$ documentário é estruturado em partes: na primeira, uma série de pessoas, especialistas, pedagogos, sociólogos, artistas, educadores formais e informais falam sobre a importância do lúdico na vida humana. Na segunda parte o entrevistado tem a tarefa de resgatar na memória uma imagem da infância e descrevê-la para a câmera. Além disso, pede-se que eles imaginem o que diriam a essa criança, que brincadeiras ainda fazem e, em caso negativo, por que não. A força dos relatos no vídeo inspirou a trazer a prática para as enfermarias. A primeira oportunidade ocorreu em 13 de maio de 2016, a convite da equipe de Serviço Social, com o grupo de acompanhamento de pacientes com hanseníase. A ideia era exibir o filme e, na sessão seguinte, que os pacientes trouxessem fotos da infância e falassem sobre elas, construindo narrativas. Assim foi feito. A ideia era sensibilizá-los para a questão do cuidado de si. O filme mergulha de cabeça no "território sagrado" da infância, resgatando memórias mais profundas e dialogando com as crianças que os entrevistados foram e no que diriam atualmente para essas "crianças". Aí a emoção fala mais alto, os olhos brilham e os rostos se contraem, tentando segurar o choro. Assim também foi na sala do HUCFF. Ao final do filme, muitos estavam emocionados. Outros sorriam sem parar e outros, ainda, tinham o olhar perdido na infância que haviam acabado de revisitar.

Ao término do filme foi feita uma roda de conversa bem rápida e todos pareceram ter gostado. Na semana seguinte a tarefa era trazer as fotos de infância e contar histórias sobre elas. A primeira foi a assistente social responsável. De posse de uma pequena fotografia, ela iniciou sua fala, mas logo silenciou. As lágrimas tomavam seu rosto e ela não conseguia continuar. Logo foi consolada por um dos participantes e pôde concluir seu relato. Minuciosamente ela falava da infância, do ambiente que cercava a fotografia, da roupa que usava e até do que sentia naquele momento. Em cada elemento compartilhado, as expressões de todos os presentes mudavam e, enquanto esperavam sua vez de mostrar suas fotos, iniciavam conversas paralelas, aos cochichos. A cada fala, era solicitado que descrevessem as brincadeiras de infância, as sensações e experiências e se ainda se reconheciam e praticavam esses jogos. Imediatamente os olhos se turvavam, iam longe, mergulhavam nas imagens que vinham à memória. Naquele momento parecia ser delineado um território comum, feito tijolo a tijolo pelas memórias individuais, na fala e na escuta compartilhada.

Nesse lugar criado, as emoções surgiam como potência de ação, onde os sujeitos pareciam apropriar-se de seu próprio tempo, reconhecendo e ressignificando sua história na medida em que esta era dividida com os demais. Ali, foi possível identificar uma aproximação com o que Jaccques Rancière (2012) pontua sobre a condição do espectador, ou seja, que o ato de observar também é uma forma de agir. Assim, o lugar do espectador também confere a este certa igualdade em uma experiência estética, passível de "reconfigurar a paisagem do perceptível e do pensável, modificar o território do possível e da distribuição das capacidades e incapacidades" (Ibid.: 73). Há então um compromisso nesse lugar de fala e de observação, que demanda uma leitura de mundo e pode subverter a ordem natural das coisas. A arte, nessa perspectiva, pertence ao mundo da vida e não pode ser dissociada desta, sendo inevitavelmente política. Consequentemente, se a experiência com a narrativa do filme pode ser emancipatória, ela o será, posto que atravessa a tela, expande-se nos diferentes sujeitos, torna-se fonte de sociabilidades e, assim sendo, um processo comunicacional por excelência. Assim, dialoga com a ideia de cinema expandido, cuja profundidade será investigada a seguir.

Aqui se faz necessário um breve recuo, para que se possa observar as transformações da produção artística nos últimos anos, as quais influenciaram profundamente o modo de fazer cinema, expandindo-o em suportes e narrativas. A reboque dos anos 1960, o cenário artístico cobria-se de performances em 
múltiplos meios, caso da coreografia de Merce Cunningham e dos happenings de Allan Kaprow (REZENDE; MACIEL, 2013). Entre instalações, na explosão do texto e da palavra em distintas materialidades, a arte reforçou o sentido de multiplicidade e ressignificou a ideia de suporte, dialogando com um tempo cada vez mais plural. Não é à toa que, nessa mesma época, Paul Jackson Pollock, pintor norte-americano, tornou o quadro menos importante do que o processo em suas famosas performances (ARGAN, 1992).

Mobilizações como essas objetivavam questionar o conceito de arte, sua função e suportes, e essas questões foram reforçadas pela perspectiva da poesia concreta que, segundo Katia Maciel, "dinamitou a frase, o encadeamento sintagmático padrão, para construir 'ideogramas'” (RISERIO, 1998: 85 apud MACIEL, 2009: 9). As formas estéticas afirmavam-se como invariavelmente plurais e tornavam a arte um elemento não mais do tempo e sim do espaço (REZENDE; MACIEL, 2013), posto que o tempo, como já propusera Pollock, é feito de não duráveis. E se as artes caminham no sentido do efêmero, libertas das limitações do meio, com o cinema não poderia ser diferente. De tal maneira que, a seu tempo, Youngblood (1970) e Katia Maciel (2009) construíram a ideia de cinema expandido, em que a narrativa fílmica se associa a diferentes dimensões estéticas.

Expandir o cinema seria pensar um outro tempo e espaço, por suportes e formas distintos do que André Parente (apud MACIEL, 2009: 9) entende como a perspectiva das três dimensões: "a arquitetura da sala, herdada do teatro [...], a tecnologia de captação/projeção [...] e a forma narrativa estética ou discurso da transparência adotado pelos filmes no fim do século XIX". Assim, o cinema seria um dispositivo tridimensional e, portanto, discursivo, cujos elementos concorrem para gerar um efeito de "subjetivação no corpo social, seja ele de normalidade ou desvio, territorialização ou desterritorialização" (Ibid.: 26). Ainda para a mesma autora, a ideia de expansão, aplicada às experiências hospitalares com o cinema, alarga as fronteiras do cinema-representação, configurando-se em visões outras de mundo, disposições culturais e experiências sensíveis, ocupando o espaço do hospital. Esse espaço existe em virtude de todos os seus possíveis movimentos contrastantes entre distâncias e proximidades, em que o corpo enfermo, que é parte da razão sensível, posta-se diante de um universo de imagens difícil de apreender. Ainda assim, o lugar parece fervilhar de vozes e narrativas e, a cada esquina, novas histórias se apresentam, combinando realidade e poesia. Basta saber escutar.

Mais do que nunca, é necessário encontrar uma linguagem que possa atravessar os muros de silenciamento, cansaço e tristeza, e falar aos afetos dos pacientes. A cada dia é necessário encontrar o elemento que os convocará e os trará para o debate, para o espaço em comum. E geralmente esse elemento é a música, como linguagem universal que, uma vez acionada, cria um imaginário de memória coletiva, sensível, tocando a todos, sem diferença de idade ou estado de saúde. Em algum lugar da memória de cada um as músicas do filme reverberam, criando paisagens sonoras quase palpáveis. Com Tarja branca não é diferente. Há, entretanto, o componente da memória, para reverberar para além da música e propor pontes.

Na segunda experiência, dois meses mais tarde, a única diferença em relação à primeira era que os pacientes estavam desprevenidos, então ninguém tinha a foto nas mãos. Era impossível não lembrar de Roland Barthes (1984: 84), quando o autor observara que "para ver uma foto mais vale erguer a cabeça ou fechar os olhos". Assim também aconteceu na enfermaria. Os pacientes, por vezes com olhos perdidos, semblantes fechados, então buscaram nos cantos mais remotos da memória suas imagens de infância, compartilharam histórias e impressões. Em relação às brincadeiras de infância, um pouco de cada um era partilhado nas falas, saindo do relato individual e se tornando ficcional, indo ao encontro do que Rancière (2014: 203) compreendera da ficção, como "construção de um conjunto de relações entre uma percepção e outra percepção", de sujeito a sujeito, fazendo-se plural. 
É possível perceber, nas práticas com o filme, uma invenção coletiva, como se as memórias alheias, ressignificadas e trazidas de volta do distante baú da infância, fossem então colocadas no meio da sala, para serem experimentadas também por todos. Nessa imagem que não se pode ver, apenas sentir, há um "aprendizado da realidade do mundo por meio das experiências, em que o olhar, sendo um recorte, uma janela que desvenda o mundo, se abre para o outro.

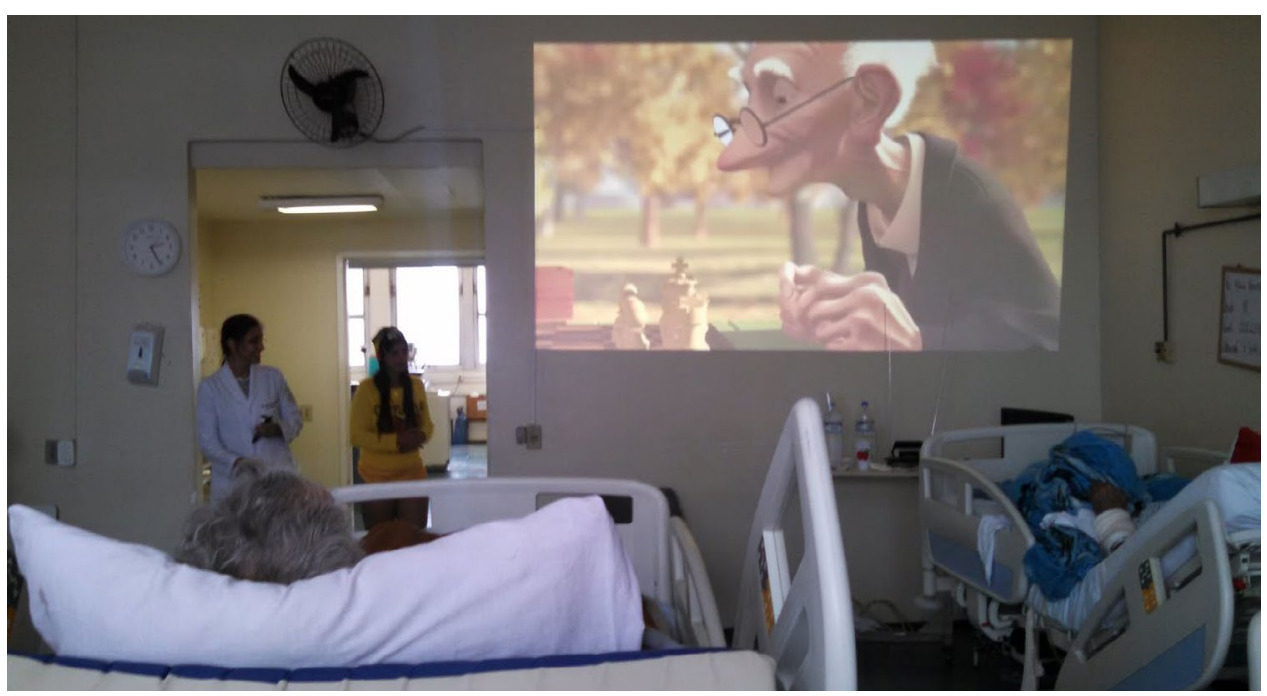

Figura 3: Registro da sessão 2 - curta de abertura.

Todos os participantes se tornam, assim, doadores dessa paisagem que se descortina. Diante dos olhos de cada um a emoção do contato com a memória mais escondida da infância se faz intensa, posto que é coletiva, unindo a todos na mesma condição de humanidade e, de alguma forma, em igual relação com o tempo.

Há uma caminhada na análise das projeções, que advém da ideia de imagem como pensam, cada um a seu modo, Didi-Huberman (2013) e Jacques Rancière (1988). Logo é possível identificar, em consonância com Huberman, a imagem como sobrevivente ao tempo; também é necessário compreendê-la, em Rancière, como sustentáculo da estrutura social, que une passado e presente na medida em que, por meio dela, uma narrativa é construída. Seria o caso de pensar que cada um dos pacientes, ao acessar a infância, cria para si um território sensível, espécie de ordenamento da memória, interno ao sujeito, em que a narrativa será o lugar vivido e ressignificado. $O$ olhar de cada um é a imagem que se localiza no tempo, segundo um determinado estado de coisas. Pensar a memória da infância será, em igual medida, identificar o sujeito na imagem, permear os diálogos com o tempo de corpo e emoções, no universo sensível. O passo além do enquadramento que se faz ao convocar uma fotografia é o caminho para o "punctum", esse elemento de pungência que, apesar de invisível, é facilmente identificado por todos os participantes. Afinal, quem não se reconhece no olhar perdido, nas lágrimas contidas, ao vislumbrar o rosto da criança que fora um dia, tão comum a ponto de convocar o afeto e acessar, instantaneamente, as próprias memórias?

A imagem, dessa maneira, vai além do que pretendera Barthes (1984) ao analisar fotografias familiares, também estas feitas de afeto, memória e narrativas. Em vez de somente unir presente e passado, une e emancipa os sujeitos do passado com os do presente, compartilhados por meio da narrativa. Também em Rancière (2012) tal emancipação encontra eco. Não por acaso, na obra $O$ espectador emancipado, Rancière compreende que o ato de observar também é uma forma de ação. Nesse lugar, o espectador, em uma experiência estética, é passível de "reconfigurar a paisagem do perceptível e do pensável, modificar o território do possível e da distribuição das capacidades e incapacidades" (Ibid.: 73). Há 
então um compromisso nesse lugar de fala e de observação, que demanda uma leitura de mundo e pode subverter a ordem natural das coisas. A arte, para Rancière, pertence ao mundo da vida e não pode ser dissociada desta, sendo inevitavelmente política, esteja ela projetada em uma tela de cinema ou sob os biombos da enfermaria hospitalar.

\section{Considerações finais}

Contrariamente ao que pensara Walter Benjamin (2012) sobre a modernidade, em tempos em que a comunicação se transmuta nos microrrelatos, em diferentes meios, por vezes transmidiaticamente, parece tornar-se cada vez mais distante o tempo em que a experiência do choque gerará mudez. Ao contrário. A verdade é que, independente do caminho, o sujeito continuará a ser atravessado, construído e desconstruído por narrativas. Elas atravessam cada segundo da vida, desde os murmúrios ouvidos ao nascer, passando pelas canções da hora de dormir, até o glorioso momento em que o letramento permite o mergulho no universo das palavras e imagens. Para cada um, o contato com a narrativa guarda um pouco de magia, esteja ela nas mãos e vozes dos antepassados, avós ou nas páginas coloridas dos primeiros livros. E assim, enquanto seres simbólicos, aprende-se a dialogar com o tempo das coisas, nos costumes, valores e enquadramentos, invariavelmente dispostos em um contexto sócio-histórico específico.

Em cada capítulo da vida, aos poucos busca-se perceber a organização dos personagens, a mise en scène de cada momento, a fala adequada a cada ocasião. Nesse intervalo, lá fora a janela das memórias permanece intocada, sendo raramente acessada nas horas cotidianas. Ficará a cargo do cinema, enquanto imagem em movimento, fragmento de tempo e espaço, o ofício de propor olhares e recortes por sobre o estado de coisas, criando condições de possibilidade para que surjam territórios em comum, feitos de afeto e sensibilidade.

Entre uma imagem e outra pode-se entender e recriar o mundo, posto que há um real que extrapola as margens da tela, demandando reflexão e crítica. 0 filme não pode ser maior do que o sujeito, ele não o ultrapassa, mas o convida a dialogar com ele. É preciso não se deixar levar pelo devaneio, permanecendo de olhos abertos para ouvir o ruído de cada uma de suas engrenagens e apreciar sua beleza. $\mathrm{O}$ que faz sentido, em harmonia com o conjunto de símbolos que se chama existir, este é o verdadeiro tempo do cinema e o que lhe confere a técnica da arte que se propõe a representar. Não é algo além do homem, faz parte dele e se construiu de sua singular capacidade de significar. É tempo e arte, fragmento e todo, real e ilusão, para o homem e por ele.

$E$, à guisa de conclusão, afirma-se neste artigo que, se o cinema se insere no tempo das práticas sociais desde sua origem, o faz pelo caminho de experiência sensível que invariavelmente é. Sob esse aspecto, será no exercício de debruçarse sobre a realidade (plural e multifacetada, provisória e efêmera) e estabelecer recortes (por meio da montagem), observando os mecanismos internos dos fragmentos das imagens em movimento, o meio de mergulhar no mundo, em suas engrenagens, sensibilizando-se pelo visto mas, em oposição, também por aquilo que não se vê e não se pode ouvir, mas sentir. Ante a torrente imagética do cenário social é preciso recortar, analisar, tornar coletivos e reagrupar fragmentos de vida. A imagem torna-se fundamental, como método inescapável de apreensão e transformação da existência.

A arte e a experiência coletiva, à parte todos os esforços, não serão sempre suficientes para transformar o mundo e não conseguem pôr abaixo muros de desigualdade. Podem, entretanto, mudar pessoas e fazer com que seus olhares possam convergir para o outro, fazendo-o parte de si e tornando a vida cotidiana mais dialógica e plural. As memórias não serão assim apenas recortes de mundo, mas necessárias para que os sujeitos possam apropriar-se de suas narrativas 
e todos os demais discursos e silenciamentos que os cercam. Logo, podem compreender a infinidade de roteiros e personagens distintos que existem em suas vidas, trilhando como seres conscientes o caminho da contemporaneidade.

\section{Referências}

ARGAN, G. C. Arte moderna. Tradução Denise Bottmann e Federico Carotti. São Paulo: Companhia das Letras, 1992.

ARFUCH, L. O espaço biográfico: dilemas da subjetividade contemporânea. Tradução Paloma Vidal. Rio de Janeiro: UERJ, 2010.

BARTHES, R. A câmara clara: nota sobre a fotografia. Tradução Júlio Castañon Guimarães. Rio de Janeiro: Nova Fronteira, 1984.

BENJAMIN, W. Magia e técnica, arte e política: ensaios sobre literatura e história da cultura. Tradução Hemerson Alves Baptista e José Carlos Martins Barbosa. 8. ed. São Paulo: Brasiliense, 2012.

BERGSON, H. Matéria e memória. Tradução Paulo Neves. São Paulo: Martins Fontes, 1999.

DELEUZE, G. Bergsonismo. Tradução Luiz Orlandi. São Paulo: Editora 34, 1999.

DIDI-HUBERMAN, G. A imagem sobrevivente: história da arte e tempo dos fantasmas segundo Aby Warburg. Tradução Vera Ribeiro. Rio de Janeiro: Contraponto, 2013.

MACIEL, K. (Org.). Transcinemas. Rio de Janeiro: Contra Capa, 2009.

MAFFESOLI, M. Elogio da razão sensível. Tradução Albert Christophe Migueis Stuckenbruck. Rio de Janeiro: Vozes, 1998.

MARTINS, A. F. Cinema de terras e fronteiras. In: MASCARELLO, F. (Org.). História do cinema mundial. Campinas: Papirus, 2006. p. 395-412.

PASSOS, E.; KASTRUP, V.; ESCÓSSIA, L. (Orgs.). Pistas do método da cartografia: pesquisa-intervenção e produção de subjetividade. Porto Alegre: Sulina, 2009.

RANCIÈRE, J. A noite dos proletários: arquivos do sonho operário. Tradução Marilda Pedreira. São Paulo: Companhia das Letras, 1988.

. O espectador emancipado. Tradução Ivone Castilho Benedetti. São Paulo: WMF Martins Fontes, 2012.

Em que tempo vivemos? Revista Serrote, Rio de Janeiro, n. 16, p. 203222, abr. 2014.

REZENDE, R.; MACIEL, K. Poesia e videoarte. Rio de Janeiro: Circuito; Funarte, 2013.

TARJA branca AKA Drops of Joy 2014 Filme Nacional Completo. 89'06". Filmes Alternativos. YouTube. 2017. Disponível em: <https://goo.gl/bQzxCA >. Acesso em: 27 out. 2017.

XAVIER, I. (Org.). A experiência do cinema. 2. ed. rev. e aum. Rio de Janeiro: Graal: Embrafilme, 1991.

YOUNGBLOOD, G. Expanded cinema. New York: P. Dutton, 1970. 